\title{
Sobre A memória rota: ensaios de cultura e política, de Arcadio Díaz-Quiñones \\ Pedro Meiva Monteivo
}

A RCADio Díaz-Quiñones, cujo primeiro livro em português acaba de ser lançado no Brasil, participa de uma longa tradição das esquerdas latino-americanas, que procura reagir aos dogmatismos, bem como ao enrijecimento do pensamento crítico, em situações de flagrante e por vezes sutil desequilíbrio do poder.

O texto a seguir é uma versão adaptada da introdução que escrevi ao livro $A$ memória rota: ensaios de cultura e política, com a intenção de apresentar o seu pensamento ao público brasileiro.

Comecemos pelas ilhas e pelas palavras.

Crítico da cultura e da política em espaços periféricos, Arcadio Díaz-Quiñones nasceu em Porto Rico e vive nos Estados Unidos, onde escreve e ensina há mais de trinta anos. Como para muitos de seus compatriotas, a diáspora é para ele condição de existência, modulada pelas circunstâncias da vida: a um só tempo cidadão norte-americano e porto-riquenho de origem, posicionado no centro da vida acadêmica, mas olhando além dela.

O Caribe, onde é muito forte a marca do colonialismo, é insular não apenas no sentido geográfico. Suas ilhas, entregues por vários séculos à gula dos impérios, tiveram fronteiras instáveis e até hoje possuem limites tênues, tanto no plano linguístico quanto no identitário. São lugares de passagem e transição, onde tudo termina sendo mais fluido, inclusive as categorias e as palavras usadas para explicar a vida em sociedade. Trata-se de um espaço que parece desbordar-se continuamente. Para um país como o Brasil, cujo sonho de autossuficiência é tão persistente, senão mesmo asfixiante, talvez haja muito que aprender com esse transbordamento que as ilhas e suas palavras ensinam a ver. Mas antes é preciso traduzir uma realidade à outra, colocando-as em contato.

Contudo, a tradução empaca diante de uma palavra original. O primeiro capítulo de A memória rota, "De como e quando bregar", traz no título um enigma. Como traduzir ao português o verbo "bregar", amplamente utilizado entre porto-riquenhos - dentro e fora da ilha - e presente em algumas outras áreas hispanófonas do Caribe? Quem brega não é um briguento, apesar da origem vocabular comum. Sabe bregar aquele que consegue lidar delicadamente com uma situação difícil, evitando a dureza do confronto definitivo e desviando-se da frieza das relações burocráticas. " $E s^{-}$ toy bregando" significa que se vai lidando como se pode, tão humanamente quanto possível, com uma situação mais ou menos adversa. Numa de suas primeiras e sempre provisórias definições, "a arte de bregar” é, segundo Díaz-Quiñones, “um método difuso e sem alarde para navegar a vida cotidiana, onde tudo é extremamente precário, cambiante ou violento". Sem alarde: navegação sinuosa, às vezes silenciosa e humilde, sempre alerta, frequentemente lépida e solerte, mas nunca definitiva. 
A brega pode ser séria, embora nunca seja pesada. Quem brega (pronuncia-se "bréga", com o "e" fechado) sabe estar jogando com um adversário mais forte: o poder, as instituições, o preconceito, o racismo, as barreiras de gênero, a própria linguagem. Em português, poderíamos dizer que somente brega aquele - ou aquela - que brinca com o perigo, porque conhece a força do inimigo e sabe que só pode dobrá-lo à custa de gestos muitas vezes ambíguos, cujo sentido é resvaladiço. Quem brega não quebra as estruturas nem rompe o tecido social, mas aprende a respirar, numa navegação complexa e arriscada. ${ }^{1}$

Como verbo, bregar pode ser transitivo (brega-se com algo) ou intransitivo (vou bregando). Como substantivo e conceito, a brega tem a ver com amoldar-se, adaptar-se e encontrar espaço para a ação livre, num vaivém que é também uma negociação surda. Como lemos na entrevista que se encontra ao final de $A$ memória rota, a brega é "o contrário da guerra aberta”. Seu fundamento são as palavras e os gestos capazes de ensejar movimentos sutis, resistentes ao desenho claro e definido do ato heroico. A brega é uma gesta do cotidiano, a "arte do nãoépico". Nesse mundo de heróis desconhecidos e pouco estridentes, a força do sujeito só pode residir num realismo tácito e digno. "Perdida a dignidade, a brega fracassou".

Mas o realismo, nesse caso, não se resume à passividade ou à desistência de mudar o mundo, embora se identifique mais com a arte abnegada dos reformadores que com a sanha destemida dos revolucionários. Como crítico caribenho e intelectual latino-americano engajado, o autor de $A$ memória rota dialoga com as tradições de esquerda ao lon- go do século $\mathrm{XX}$, com o imperialismo norte-americano, com o materialismo e o arrivismo da sociedade capitalista, brigando (ou bregando) com as identidades fixas e as interpretações canônicas da história nacional nos marcos colonial e pós-colonial. Contrapondo-se a uma noção rígida e empobrecedora da política, procura descobrir o lugar onde o sujeito se revela, entre o arrebatamento da ação extrema, de um lado, e a batalha miúda do cotidiano, de outro. Mas que luta instável e delicada será essa, expressa na "arte de bregar"?

Já se terá notado que, conquanto dotado de suas singularidades, o contexto que produziu o verbo bregar pode estar próximo do Brasil. A ideia de uma cultura política que depende dos desvios, do jogo permanente com os sentidos, bem como da capacidade de amoldar-se, nos aproxima de algumas das mais insistentes fantasias sobre um estilo nacional brasileiro, o qual se projetaria na soltura alegre das curvas, mais que na chata rigidez das retas. Tais fantasias, que deitam raízes em Gilberto Freyre (embora no contexto cubano pudéssemos pensar num antropólogo da envergadura de Fernando Ortiz), podem ser enganosas, ao sugerir que o crítico cultural estaria em busca de uma essência, ou de um caráter que a colonização portuguesa teria legado ao Brasil, e que a vida em colônia teria cuidado de amaciar, no doce amálgama da sociedade escravista. No entanto, nada mais contrário à brega que essa grande idealização de uma civilização tropical.

Se fosse preciso reduzir tudo a uma fórmula, poderíamos dizer que a brega é capaz de injetar, no desenho edulcorado da civilização tropical - tendo a experiência colonial e escravista em seu âmago 
-, nada menos que a política. No traçado sinuoso da brega não está apenas a experiência de um sujeito maleável e dócil. A arte de bregar é também a possibilidade do ataque e da defesa, bem como da precisão e da sabedoria iletrada ou semiletrada: o sujeito se dobra para não quebrar, mas regressa sempre ao círculo da luta, tão forte e digno quanto possível. Seu império é instantâneo e pode desaparecer a qualquer momento, como se o indivíduo fugisse do golpe fatal para manter-se em pé, num baile incessante com o poder e a morte. Seus gestos, ademais, têm no grupo e na comunidade sua régua e seu compasso. A brega, para esse pensamento cheio de vozes e de música, é também uma arte da fuga. ${ }^{2}$

Para traduzir a "proteica palavra", como a chama Díaz-Quiñones, pensei, durante muito tempo, que a solução seria brincar com o título de uma obra polêmica da tradição colonial luso-brasileira, $A$ arte de furtar, a que eu adicionaria um pronome reflexivo, chegando a uma fórmula feliz: "a arte de furtar-se". Contudo, para além da menção erudita, que se casava mal ao espírito leve da arte de bregar (afinal, quem conhece $A$ arte de furtar, nos dias de hoje?), havia um problema conceitual na tradução. A questão é que a brega não é apenas evasiva, nem exclusivamente defensiva. Um sujeito que "se furta" está evitando a luta, enquanto o sujeito da brega é um lutador constante, ainda que reconheça a necessidade imperiosa de recuar. Na verdade, sua autonomia é tão mais forte quanto mais ele - ou ela - consiga intuir o momento de retirar-se de campo, quando não há mais nada a ganhar. Há muita dignidade em saber quando e como sair. Mas sair, nesse caso, não significa furtar-se à política.
Numa batalha diária em que os marcadores étnicos, de gênero e classe social são para valer, o sujeito da brega está de olho na recompensa de permanecer vivo, mais que na promessa abstrata da glória, ou na fantasia enganosa da vitória definitiva. A vida, claramente, é sua aposta mais alta. Se não se trata de um anti-herói, tampouco estamos diante da vítima a ser imolada no altar da coletividade, para salvação de todos. Sua luta tem a ver com a preservação, não com a entrega do corpo a uma causa superior. A tortura, o terror, a ditadura, a luta armada, a política e a religião são pontos de fuga na investigação histórica e cultural de $A$ memória rota, que é também - para retomar a metáfora polifônica uma invenção a várias vozes.

Que outras expressões evocariam, em português, a arte de bregar? Ao conversar com o autor, notei que um vocábulo o fascinava: a ginga. Mas como utilizar o léxico da capoeira, se ele sem querer carrega um pouco da ideologia do Estado Novo (1937-1945)? Como arte popular afro-brasileira, a capoeira não engrossou as políticas culturais do período? Uma "arte da ginga" acabaria por evocar um "jeito" (outra palavra cheia de complicações) que correria o risco de apontar para uma característica essencial, mais que para uma estratégia cambiante de liberação. Como trabalhar entre o dito e o não dito dessas expressões? Como evitar o vocabulário ideologicamente carregado?

Buscando outras metáforas, e conversando com outras pessoas, aprendi mais sobre a fluidez da significação. Deveríamos então arriscar uma metáfora marinha, evocando as artimanhas da navegação em águas tempestuosas? Ou a brega seria algo como uma esquiva no 
boxe? ${ }^{3} \mathrm{E}$ as metáforas do futebol, quão úteis seriam? Estaríamos diante de uma "arte de driblar"? Mas o que significa contornar os obstáculos? Driblar é simplesmente uma maneira de escapar, ou é a forma mais inteligente de enfrentar-se a um adversário poderoso? A brega não tem a ver também com o avanço por um território ainda não mapeado? Mas que sabedoria seria essa, mergulhada na contingência do instante, arisca e resistente ao planejamento? Onde estão os vetores da política, e como se resguarda a subjetividade, quando se pensa num sujeito capaz de bregar? Estaríamos diante de um outro "conceito do político"?

São todas questões em aberto, a que A memória rota responde com novas questões, e com uma miríade de referências que hão de surpreender o leitor brasileiro, pois algumas the serão familiares, enquanto outras serão completamente novas. Ainda assim, mesmo o quadro teórico mais familiar ganha um giro e uma velocidade inéditos, ao incidir sobre espaços tão porosos como as ilhas do Caribe, ou mesmo sobre Nova York e as grandes cidades da diáspora caribenha. De uma forma ou outra - voltando ao título do ensaio -, como tradutor, terminei por baixar a guarda, deixando a expressão em espanhol, em itálico: a arte de bregar.

Já o segundo capítulo de $A$ memória rota, intitulado "Hispanismo e guerra", é uma longa e bem informada reflexão sobre o poder das palavras num contexto imperial. O que significa dizer "hispânico" ou "hispano-americano", e que dimensão ganham os nomes e as identificações no momento da disputa pelas colônias? Nomear já é fazer política. Evocando a reflexão de Edward Said sobre os “inícios" (beginnings), Arcadio Díaz-Quiñones explora o instante em que, durante a guerra de 1898 entre a Espanha e os Estados Unidos - quando Cuba e Porto Rico passariam à esfera de influência norte-americana, assim como acontecia com as Filipinas, no Pacífico -, a perda das colônias enseja a produção intensa de imagens e histórias que muitas vezes querem legitimar a conexão que se perdia com o Império espanhol.

A "Historia" da literatura hispano-americana de Marcelino Menéndez Pelayo (1856-1912), produzida justamente no momento em que a Espanha perdia suas possessões no Caribe, é o eixo em torno do qual gira a atenção do crítico, interessado em verificar como se constroem os princípios de uma disciplina - o "hispanismo" que dá título ao ensaio - e de todo um campo do saber que vê o hispano-americano como caudatário de um centro irradiante de cultura, localizado necessariamente na Europa. Mais que ignorar a produção local americana, tratava-se de incorporá-la numa fala autorizada, capturando as obras "hispano-americanas" numa rede discursiva que as remetia a sua gloriosa origem "hispânica". Na impossibilidade de vencer o poderio bélico e imperial norte-americano, construía-se um império simbólico: o da língua e da literatura "hispânicas", que compensava a perda dos territórios antes submetidos ao poder espanhol.

O Brasil nunca se viu tão claramente - ou tão dramaticamente - jogado entre impérios, como o Caribe. No seu período propriamente moderno, desde quando a ideia da "nação" já fazia sentido, em pleno século XIX, o país teceu um discurso nacional a partir da recusa simbólica das origens europeias, especificamente portuguesas, que iria da idealização do autóctone pelos românticos à construção 
bem-humorada das coisas "brasileiras" pelos modernistas, já bem entrado o século XX. O caso do Caribe é diverso, porque se trata de um espaço em litígio militar. Interessa então compreender como a cultura reage à guerra, adaptando-se, recriando e sustentando poderes internos e externos, num complexo e delicado jogo em que as línguas, os nomes e as imagens estão em constante negociação, e quando o mundo letrado se vê confrontado a outros mundos, ora fascinantes, ora perturbadores. A memória rota é também sobre a interface entre práticas artísticas de elite e populares, sobre espaços intermediários onde sujeitos históricos, classes sociais e etnias estão em diálogo, em meio a uma batalha simbólica incessante em que a imaginação nacional é sempre, inevitavelmente, insuficiente.

Milhares de relatos se produzem, dando forma e sentido à história, mas também reservando lugares específicos a cada um. O legado escravista, o racismo, os preconceitos de toda ordem ativam uma máquina de contar histórias que produz heróis e traidores, representantes legítimos e ilegítimos, bons e maus escritores, culturas mais ou menos autorizadas, deixando na sombra quem não interessa, criando zonas de silêncio que o crítico esquadrinha e traz à luz. Para tanto, é preciso compreender como se constroem os princípios, ou seja, como se conta uma história. A guerra entre impérios exige que se comece de novo a história, que ela seja contada de uma outra forma, num momento em que é preciso recomeçar mais uma vez, inclusive no plano da linguagem. A intensidade e a velocidade desses recomeços, ou desses "inícios" que nunca cessam de produzir-se, podem ser inéditas, para um estudioso do Brasil.
O terceiro capítulo de $A$ memória rota, "A guerra simbólica: 1898", dialoga com o capítulo anterior e lhe dá concretude, porque se detém nas imagens que a guerra entre os Estados Unidos e a Espanha produziu. Um conjunto impressionante de fotografias e imagens, recolhidas junto a coleções privadas e públicas, bem como em publicações hoje esquecidas, permite entender como se imaginava o espaço colonial, e como se enquadravam nele as pessoas que o habitavam, assim como as que vinham como soldados e - tão pronto a paisagem serenasse - como turistas e negociantes. "Decifrar, comentar, reproduzir são formas de posse: é parte da larga experiência colonial."

A proximidade entre o mundo midiático e o poder, entre a propaganda e a política de Estado, assim como a circulação das notícias e a produção simbólica do espaço fazem pensar, é claro, também nos nossos dias. Se a televisão, o rádio e a internet não eram ainda presentes, a transmissão de imagens em livros, panfletos, cartões-postais e publicações oficiais ou semioficiais era intensa, acompanhando e dando forma aos relatos que se produziam, a partir da entrada em cena de um novo Império, isto é, os Estados Unidos, com sua sempre ambígua defesa do espaço "americano". Mas tudo aquilo que já existia nas ilhas devia entrar em algum tipo de consonância com as expectativas e os gostos de quem chegava - ou de quem invadia, a depender do ponto de vista.

Como no caso da descoberta do Novo Mundo, que começara séculos antes justamente naquela área do Caribe, tratava-se agora, na virada do século XIX para o XX, da invenção de um outro mundo novo, em que a domina- 
ção imperial moderna ganharia as mais sofisticadas formulações. Diante dessa imaginação renovada da paisagem social e natural - que é também uma forma de recomeçar a contar a história - surgem novas disputas, num espaço jogado entre interesses humanitários e comerciais, científicos e bélicos. Várias das imagens então criadas parecerão estranhamente familiares a nós. Afinal, gostemos ou não, somos os herdeiros das guerras coloniais, praticantes e consumidores de formas de turismo e conhecimento que têm, em sua raiz histórica, a dominação e o conflito, o apagamento de velhas histórias e a construção de novas. "A guerra não terminou", é a conclusão desconcertante a que somos levados.

O quarto capítulo, "Espiritismo e transculturação: Fernando Ortiz e Allan Kardec", parte também de uma reconsideração dos "princípios", ou dos beginnings que dão coerência e significado à história. Nesse caso, como nas melhores histórias dos intelectuais, o crítico revisita os inícios de um pensamento: o do antropólogo cubano Fernando Ortiz (18811969), autor do famoso Contrapunteo cubano del tabaco y el azúcar (1940), onde é utilizado o termo "transculturação", que teve especial penetração teórica no universo acadêmico latino-americano e caribenho, ganhando as mais variadas formulações contemporâneas. ${ }^{4}$

Como alternativa à ideia então prevalecente de "aculturação", que pressupunha a perda dos traços culturais originais no caso da diáspora - e é principalmente a diáspora africana que estava em causa -, a ideia de "transculturação" oferecia um novo e sedutor balanço entre o "ajuste e reajuste" dos povos "transplantados a um Novo Mundo", expostos a um "imenso amestiçamento de raças e culturas" (Ortiz, 2002, p.254-60). Tratava-se de um modelo mais fluido, um "toma-lá-dá-cá" que marcava "um processo no qual ambas as partes da equação terminam modificadas", nas palavras celebratórias de Malinowski (2002, p.12333), na sua introdução ao Contrapunteo de Fernando Ortiz.

No entanto, os "inícios" servem, no caso do pensamento de Ortiz, para revelar uma história pouco ou nada estudada. É como se ao crítico coubesse sempre reinscrever os inícios em tramas alternativas, incorporando novas peças à história até ali contada. Em sua juventude, como revela Díaz-Quiñones, o futuro autor do Contrapunteo cubano del tabaco y el azúcar mesclava saberes diversos em torno de dois grandes eixos, que o levariam à ideia da transculturação: a criminologia e o espiritismo.

A mistura é inusitada, e pode soar estranha aos ouvidos de hoje. Mas os primeiros estudos antropológicos de Ortiz trazem uma forte marca da criminologia italiana. Seu foco inicial aponta para a "bampa afrocubana" (a malta afro-cubana) e para o estudo das religiões de origem africana em Cuba, que ele associa às taxas de crime, publicando seus primeirios achados na revista de Lombroso, Archivio di Psichiatria, Neuropatologia, Antropologia Criminale e Medicina Legale, um dos grandes esteios do classismo e do racismo inclementes do saber médico moderno, em sua aurora. A interpretação canônica do pensamento de Ortiz, ficamos sabendo, pauta-se pela sua passagem da criminologia ao paradigma da transculturação. Mas o que está de permeio? Que peças faltam ao quebra-cabeça, e que poderiam justamente ser buscadas nos seus "princípios"? Aí surge o nome de Allan Kardec 
e a importância, muitas vezes silenciada, do espiritismo na formação do imaginário científico moderno.

A etnologia racista, que Fernando Ortiz busca, entre outros, em trabalhos de Nina Rodrigues, pressupõe "estágios" diferentes na evolução humana, assim como uma linearidade evolutiva sempre assombrada de perto pelos fantasmas da regressão. Munido de leituras kardecistas, e em amplo diálogo com o meio social e cultural cubano, espremido entre referências eruditas e a realidade das ruas e do campo, mas sempre rezando pela cartilha da sociedade nacional e moderna, Fernando Ortiz colhe no espiritismo a ideia da transmigração das almas, e dos espíritos que se atrasam e se adiantam, na marcha do progresso.

Esse complicado trânsito espiritual, que Allan Kardec imaginara em outro contexto, serve a explicar por que alguns espíritos estacionam e outros avançam, enquanto outros ainda dão um "salto atrás". É pela ideia da transmigração que Ortiz passa do materialismo lombrosiano a um idealismo difuso, migrando, em seu pensamento, do "corpo" ao "espírito". O pulo entre a raça e a cultura, que Gilberto Freyre - em diálogo com algumas das mesmas fontes de Ortiz - pretende dar no Brasil, fica estampado, no caso do pensador cubano, numa mesma trajetória individual. Esse capítulo de $A$ memória rota pode suscitar estudos fascinantes de comparação e compreensão das redes de valores e discursos científicos que, bem analisadas, permitem conectar pensamentos que normalmente se estuda como independentes ou simplesmente paralelos. No caso de Ortiz, o trânsito entre o materialismo lombrosiano e uma concepção fluida do encontro das culturas em solo americano pode sugerir que, nele, combina-se um par de autores que no Brasil costumamos pensar separadamente: Gilberto Freyre e Nina Rodrigues.

No entanto, as hierarquias nunca abandonam a imaginação do jovem etnólogo cubano, que se pauta pela escala de evolução dos espíritos, uns adiantados, outros atrasados, uns capazes de mandar, outros de obedecer. Em todo caso, já no âmbito da obra que o faria famoso, trata-se de uma compreensão da transmigração das almas, como parte da tentativa angustiada de compreender a novidade do gigantesco sequestro de corpos que, conforme o campo metafórico que brilharia no Contrapunteo, vinham também com seus espíritos, através do Atlântico: “los negros trajeron con sus cuerpos sus espiritus, pero no sus instituciones, ni su instrumentario" [os negros trouxeram com seus corpos seus espíritos, mas não suas instituições, nem seu instrumental] (Ortiz, 2002, p.258).

O quinto e último capítulo do livro, que dá a essa antologia em português o seu título, "A memória rota", é um reflexão poética e crítica que parte de duas perguntas: como recordam os poetas, e como recordam as sociedades? A memória diante da morte, assim como o desejo de gravar o testemunho do sujeito angustiado pelo esvaziamento de sentido promovido pela modernização disparam as recordações do próprio crítico, que lê um de seus poetas preferidos, Luis Palés Matos (1898-1959). Como Díaz-Quiñones, embora em contexto muito anterior, Palés" assiste à ruptura da "fala comunitária" e ao desaparecimento dos lugares da memória - tudo aquilo que se condensa, neste ensaio que marcou época na crítica porto-riquenha, na imagem da "memória rota". 6 
A coexistência de passado e presente na literatura é o que permite, ao poeta e ao crítico, revisitar, com a memória, os lugares ainda plenos de sentido, que a modernização ameaça apagar. Diante do tempo voraz da seta do progresso, a imaginação poética protege aqueles lugares do esquecimento. Como diria Ricardo Piglia - autor querido e sempre lembrado por Díaz-Quiñones -, a literatura é "uma forma privada de utopia". Olhando para a crítica brasileira, poderíamos adicionar, com Alfredo Bosi (1993, p.192), que o discurso poético é "um trabalho que se faz no tempo do corpo (som, imagem) e no tempo da consciência enquanto produz sentido e valor".

$\mathrm{O}$ pequeno ensaio intitulado "A memória rota" foi concebida no início da década de 1990, apenas derrubadas as “estátuas na União Soviética” e desfeitos os governos socialistas na Europa oriental. À pergunta sobre como recordam os poetas soma-se então a questão da memória coletiva: "como recordam as sociedades?" Em meio à confusa reordenação política do mundo e diante do avanço cada vez mais despudorado do mercado, abria-se um espaço antiutópico, num momento em que o entusiasmo com a "globalização" mal podia esconder os efeitos lesivos de uma modernização a qualquer preço. Os anos 1990 eram tempos distópicos, propícios para recordar, na contramão, aqueles que pensaram o social. No ensaio, a figura do poeta é então substituída por uma personagem que se eclipsava: o intelectual militante.

No lugar de Palés Matos, surge César Andreu Iglesias (1915-1976), intelectual comunista porto-riquenho que se ocupou da história dos trabalhadores e de sua militância, e que foi editor ainda das Memorias de Bernardo Vega e autor de Los derrotados, esse último escrito quando a sombra do macarthismo era enorme em Porto Rico, e quando o país estava "amordaçado", porque, nos dourados anos 1950, "o desenvolvimentismo populista exigia a disciplina social". Los derrotados é um texto sobre o fracasso da utopia, que é recuperado por Díaz-Quiñones e lançado como uma mensagem numa garrafa, na esperança de que faça sentido, talvez num outro tempo, ou num lugar menos assombrado pela derrota dos sonhos das esquerdas.

Entretanto, no caso de Andreu Iglesias, o fracasso gerara "uma nova poética que apelava à memória compartida, uma história ainda próxima e muito dolorosa, de ilusões, cárcere, interrogatórios e dúvidas existenciais dos militantes". Em suma, trata-se de toda uma sombra que, relida à luz dos anos 1990, no contexto caribenho mas também latino-americano - com as cicatrizes das ditaduras ainda tão visíveis -, ganha novo sentido, como se a dor de uma derrota coletiva pudesse ser pensada, por meio da leitura de um texto de outra época. A memória crítica permite ouvir de novo a voz de um velho militante, exatamente quando a voz da militância ameaçava calar-se, impotente. Ao fim do ensaio, a crítica e a poesia se dão as mãos e operam sua arte teimosa, reconstruindo com minúcia o que o tempo destruía.

Restaria como alvo, então, a recuperação de "uma tradição moral, intelectual e estética" que está em poetas e pensadores, alguns deles talvez apresentados pela primeira vez ao público brasileiro. É uma tradição que está também em teóricos que leram o imperialismo a contrapelo, como Edward Said, que não à toa reaparecerá, como fonte de inspiração e 
amizade - junto a diversos outros intelectuais e artistas -, na entrevista que encerra A memória rota, realizada por dois jovens leitores brasileiros de Arcadio Díaz-Quiñones: Matheus Gato de Jesus e Fábio Nogueira de Oliveira.

$\mathrm{O}$ autor de $A$ memória rota: ensaios de cultura e política está interessado em entender e estender o convite feito por cada membro daquela tradição "moral, intelectual e estética", a qual, em certo sentido, ganha vida nova quando é recuperada. Trata-se da invenção de uma tradição de leitura, de uma comunidade utópica de intérpretes da política e da cultura, que resistem, de variadas formas, à força arrasadora do progresso material e à ideologia que a encobre.

"Em que tradição buscar abrigo" é uma das questões que atravessam o livro, e que pode servir de convite a tomar as experiências caribenhas não como um referente distante, ou como simples ponto de comparação. A arte de bregar, o hispanismo, as guerras simbólicas, a história intelectual e a memória rota são formas inéditas de se pensar as fissuras do grande discurso da modernização. Cada capítulo ilumina, a seu modo, a constituição de uma cultura política que, diante da colonização da memória, exige que se comece de novo, recosendo-se os fios da história.

Sobre esse tecido esgarçado, que se faz e desfaz ininterruptamente, Arcadio Díaz-Quiñones trabalha: lendo, dialogando, pensando, e dividindo. Seu interesse - talvez mesmo sua alegria - está em flagrar o instante preciso em que a história recomeça, quando o sentido se reata, os fios se emaranham de novo, e as pessoas podem inventar lugares em que viver é também, inevitavelmente, uma forma de resistir.
Notas

1 Penso no ensaio de Ángel Rama (1995, p.235-50), "La riesgosa navegación del escritor exiliado", onde "a apregoada unidade da América Latina" não é mais que "um chicotinho retórico dos intelectuais [usado] desde as origens independentes, [e que] esconde uma multiplicidade de culturas tão variada como as europeias". Para Rama, como para Díaz-Quiñones, o que está em jogo é a “carga emocional das palavras" utilizadas em contextos de exílio e deslocamento.

2 Há aqui um paralelo possível com o estudo de José Miguel Wisnik (2008, p.40430), que revisita o ensaísmo brasileiro da década de 1930 e constrói um tríptico, em que o otimismo exacerbado de Gilberto Freyre se contrapõe ao pessimimo da matriz materialista de Caio Prado Júnior, para encontrar, na ambiguidade de Sérgio Buarque de Holanda em relação ao legado colonial ibérico, um meio-termo, capaz de iluminar o potencial de uma cultura política em que, paradoxalmente, o tratamento elíptico dos problemas pode ser extremamente eficiente, ou - por vezes - tragicamente ineficaz.

3 As sugestões vêm, curiosamente, dos campos da história, da música e da crítica: Serge Gruzinski insistiu comigo na importância da metáfora da navegação, José Miguel Wisnik se ateve com entusiasmo à "arte de furtar-se", enquanto Chico Buarque sugeriu a comparação com o boxe.

4 Se o "latino-americano" pode ou não incluir o Brasil, e o que se pode comparar entre os mundos de fala espanhola e portuguesa, são discussões que $A$ memória rota ajuda a situar. Nesse sentido, vale a pena notar que a terminologia contemporânea carrega o peso do passado $\mathrm{CO}^{-}$ lonial, que pode ser flagrado na própria divisão dos campos a partir de línguas e regiões disputadas secularmente pelos impérios, aí incluído, é claro, o poder imperial e bélico dos Estados Unidos a 
partir das últimas décadas do século XIX. Como exemplos da utilização do termo "transculturação" em obras que marcaram época na crítica latino-americanista, veja-se: Rama (1982); Pratt (1992) (este último traduzido ao português, mas atualmente indisponível). Para um panorama do conceito na obra de Rama, com suas implicações para a relação deste com Antonio Candido e Darcy Ribeiro, veja-se: Cunha (2007). Para uma antologia de Rama em português, veja-se: Aguiar e Vasconcelos (2001).

5 A notação patronímica em espanhol funciona diversamente do português: o sobrenome paterno vem antes do materno.

6 A antologia em português contém ensaios escritos e publicados por Arcadio Díaz-Quiñones ao longo de mais de uma década, em livros como La memoria rota (1993), El arte de bregar (2000) e Sobre los principios (2006).

\section{Referências}

AGUIAR, F.; VASCONCELOS, S. G. (Org.). Ángel Rama: literatura e cultura na América Latina. Trad. Raquel la Corte dos Santos, Elza Gasparotto. São Paulo: Edusp, 2001.

BOSI, A. O ser e o tempo da poesia. São Paulo: Cultrix, 1993.

CUNHA, R. B. Transculturação narrativa: seu percurso na obra crítica de Ángel Rama. São Paulo: Humanitas, 2007.

DÍAZ-QUIÑONES, A. A memória rota: ensaios de cultura e política. Org. e trad. Pedro Meira Monteiro. São Paulo: Companhia das Letras, 2016.

MALINOWSKI, B. Introducción. In: ORTIZ, F. Contrapunteo cubano del tabaco y el azúcar. Org. Enrico Mario Santí. Madrid: Cátedra, 2002. p.123-133.

PRATT, M. L. Imperial eyes: travel writing and transculturation. London; New York: Routledge, 1992.
RAMA, A. Transculturación narrativa en América Latina. México, DF: Siglo Veintiuno Editores, 1982. . La riesgosa navegación del escritor exiliado. Montevideo: Arca, 1995.

WISNIK, J. M. Veneno remédio: o futebol e o Brasil. São Paulo: Companhia das Letras, 2008.

Pedro Meira Monteiro é professor na Princeton University, Princeton, Estados Unidos.@-pmeira@Princeton.edu

Recebido em 26.9.2016 e aceito em 10.10.2016.

I Princeton University. Princeton/Estados Unidos. 